\title{
Nature-Based Solutions for Co-mitigation of Air Pollution and Urban Heat in Indian Cities
}

\author{
Jyothi S. Menon ${ }^{\star \dagger}$ and Richa Sharma ${ }^{\dagger}$ \\ Center for Environmental Health, Public Health Foundation of India, Gurugram, India
}

The urban population is subjected to multiple exposures of air pollution and heat stress and bear severe impacts on their health and well-being in terms of premature deaths and morbidity. India tops the list of countries with the highest air pollution exposure and hosts some of the most polluted cities in the world. Similarly, Indian cities are highly vulnerable to extreme heat with the frequency of heatwaves expected to increase several-fold in urban areas in India. It is reported that mitigating air pollution could reduce the rural-urban difference of the incoming radiation thus resulting in mitigation of the urban heat island effect. Since the interaction between urban heat and air pollution is dynamic

OPEN ACCESS

Edited by:

Prashant Rajput

Banaras Hindu University, India

Reviewed by:

Sisay E. Debele,

University of Surrey, United Kingdom Atinderpal Singh,

University of Delhi, India

*Correspondence:

Jyothi S. Menon

jyothi.menon@phfi.org

tThese authors have contributed equally to this work and share first authorship

Specialty section: This article was submitted to

Climate Change and Cities,

a section of the journal

Frontiers in Sustainable Cities

Received: 04 May 2021 Accepted: 17 August 2021

Published: 08 October 2021

Citation:

Menon JS and Sharma R (2021)

Nature-Based Solutions for

Co-mitigation of Air Pollution and

Urban Heat in Indian Cities.

Front. Sustain. Cities 3:705185.

doi: 10.3389/frsc.2021.705185 and complex, both these factors should be considered by the urban authorities in designing mitigation strategies. Given the multi-functional nature and cost-effectiveness of Nature-Based Solutions (NbS), they appear to be the most appropriate remedy for environmental issues of urban areas, particularly in developing countries. In addition to improving public health (through the reduction in air pollution and urban heat), $\mathrm{NbS}$ also provides a wide range of co-benefits such as reducing energy cost and health costs as well as conservation of biodiversity. This review is an attempt to understand the potentials of $\mathrm{NbS}$ in co-mitigating air pollution and urban heat in Indian cities. A framework for the planning and design of $\mathrm{NbS}$ in Indian cities is also proposed based on the review that could help city planners and decision-makers in addressing these two issues in an integrated manner.

Keywords: nature based solution, Urban Heat Island, air pollution mitigation, air pollution tolerance index, co-mitigation

\section{INTRODUCTION}

As a rapidly urbanizing nation, India faces the challenge of developing its cities sustainably. Most cities in India have been growing organically lacking prudent planning that often results in degradation of their environment and ultimately resulting in various health implications for the citizens. Urban planners and policymakers hence need to anticipate the various environmental impacts of their plans and policies to ensure sustainable urbanization. The two major issues that cities across the globe facing are: Air Pollution (Manisalidis et al., 2020) and the Urban Heat Island (Ulpiani, 2021). Interestingly, the two phenomena are also intricately linked to each other through positive feedback loops (Figure 1). The change in urban microclimate can affect the pollutant dispersion, thus the air quality. The Short-Lived Climate Pollutants (SLCP) such as ozone and black carbon can trap heat thus increasing the temperature. Both air quality and urban microclimate are also affected by other urban characteristics such as urban morphology and 


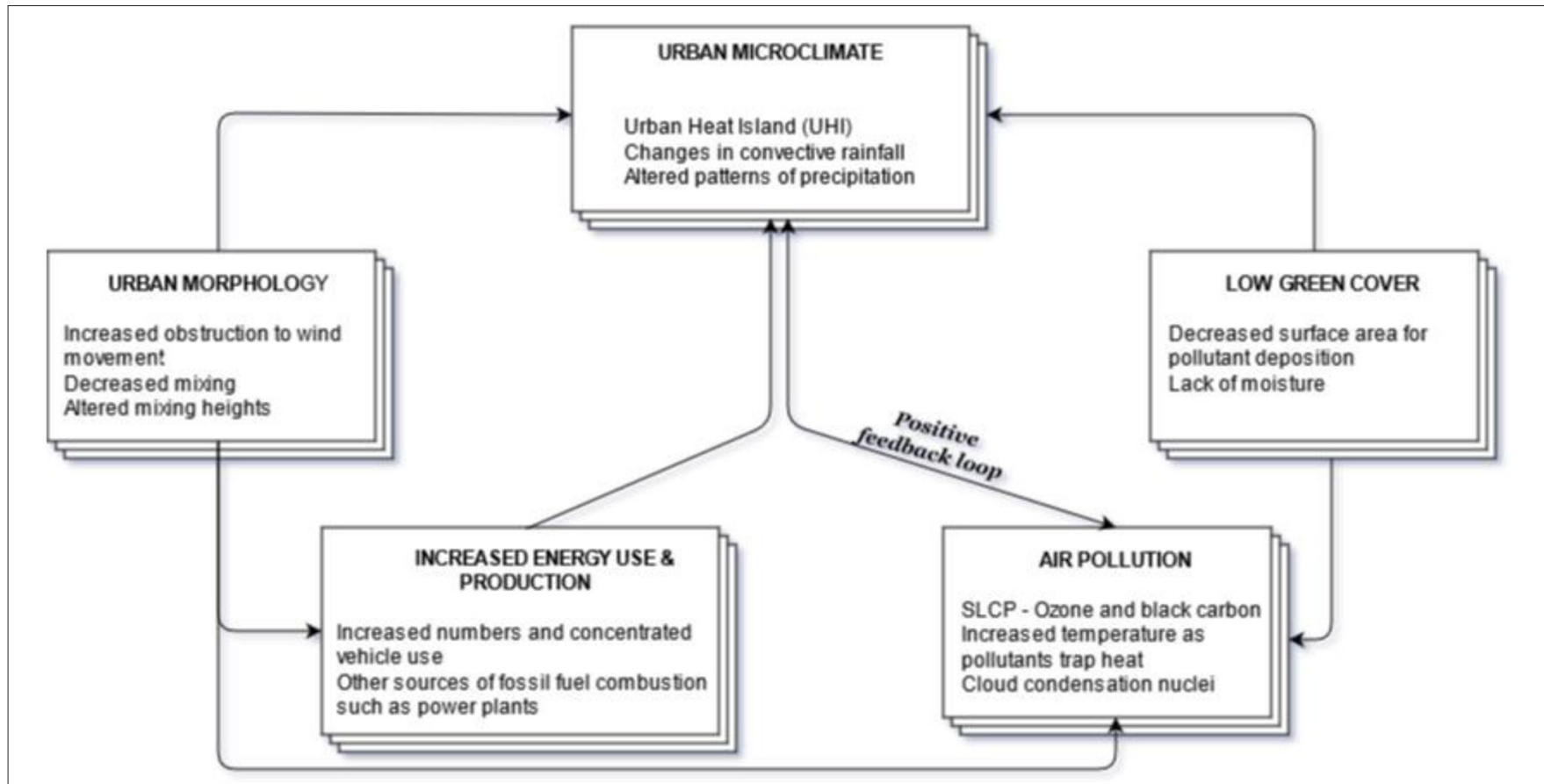

FIGURE 1 | Inter-linkages between changes in urban micro-climate and air pollution.

green cover. Hence, it is important to study the two issues together and understand their integrated exposure.

Rapid urbanization has resulted in significant changes in land use and land cover which is affecting the environment in myriad ways. Specific qualities of urban materials (e.g., low albedo and high volumetric heat capacity of concrete asphalt) (Mohajerani et al., 2017), urban morphology and design (decreased sky view factor due to densely places tall buildings) (Dirksen et al., 2019), along with the heat generated from energy usage and other anthropogenic sources (Singh et al., 2020b) increases the temperature in an urban area in comparison to the surrounding suburban and/or rural areas. The phenomenon is termed as Urban Heat Island or UHI (Oke, 1973). This works as positive feedback for escalating energy consumption through increased demands for cooling. UHI also tends to intensify the effect and impact of extreme heat and heatwave events in cities (Rizvi et al., 2019). Urbanization impacts are not only limited to direct changes in land surface and air properties, but are also characterized by increase in vehicular and industrial activities that cause further deterioration in air quality (Manisalidis et al., 2020). Rapid urbanization and industrialization also result in increased anthropogenic activities which is the main cause for the deterioration of air quality in many cities. Ample studies on changes in Land Use Land Cover (LULC) and urbanization, and its effect on urban temperature and air pollution are available in India. However, there is a significant research gap on understanding the combined exposure and mitigation of urban heat and air pollution in urban areas. This is in spite of the fact that India has a high potential for co-benefits of mitigation of air pollution and climate change.
Considering the degradative nature of the current urbanization and growth and development practices, governments across the world are increasingly investing in ecosystem-based approaches of development. Nature-based Solutions (NbS) for city planning are hence, becoming popular among policy makers and practitioners. NbS has found great applications in water and energy security, disaster management and risk reduction as well as improving social well-being in urban areas. $\mathrm{NbS}$ aims to produce more resilient cities through restoring nature which can support conventionally built infrastructure systems (Bush and Doyon, 2019). Given the multi-functional nature and cost-effectiveness of NbS, they appear to be the most appropriate remedy for environmental issues of urban areas, particularly in developing countries like India. However, not enough steps have been taken toward integrating $\mathrm{NbS}$ into the city planning process. This review is an attempt to understand the potentials of $\mathrm{NbS}$ in co-mitigating air pollution and urban heat in Indian cities. Based on this review, a framework for the successful implementation of $\mathrm{NbS}$ in Indian cities is also proposed. Such a framework could facilitate effective and efficient city planning and decision-making while addressing the two issues (discussed) in an integrated manner.

\section{METHODOLOGY}

An electronic review was carried out for peer-reviewed research articles using a combination of selected keywords ("naturebased solutions," "nature-based solution + urban," "nature-based solutions + urban heat island," "nature-based solution + air pollution," "nature-based solution + air pollution + urban heat 
island"). The articles published in the last 10 years (2010-2020) were retrieved from bibliographical databases (Google scholar, Sciencedirect, Pubmed) and from the reference lists of selected articles (Table 1). The articles that did not focus on urban areas or cities and non-English articles were excluded. The two authors independently went through the list of abstracts and finalized the articles for review.

\section{URBAN HEAT ISLAND EXPOSURE IN URBAN AREAS}

Urban Heat Island (UHI) is a phenomenon globally experienced by urban areas, wherein the urban built-up areas exhibit higher temperatures as compared to surrounding non-urban or rural landscapes (Oke, 1973). The phenomenon has been extensively documented in various cities across the world including in China (Li et al., 2018), US (Ramamurthy and Sangobanwo, 2016), Canada (Gaur et al., 2018), Australia (Santamouris et al., 2017), countries of Europe (Arnds et al., 2017; De Ridder et al., 2017), Turkey (Dihkan et al., 2018), Iran (Haashemi et al., 2016; Weng et al., 2019), Sri Lanka (Ranagalage et al., 2018), Malaysia (Qaid et al., 2016), Philippines (Estoque and Murayama, 2017), and India (Mathew et al., 2018) to mention a few with varying socio-economic and geoclimatic factors.

UHI is studied as surface UHI (SUHI) and as atmospheric UHI (AUHI). The intensity of SUHI is often measured using remotely sensed Land Surface Temperature (LST) often derived from Landsat thermal bands (Sagris and Sepp, 2017), MODIS LST products (Sidiqui et al., 2016) and ASTER thermal data (dos Santos et al., 2017). For measuring atmospheric UHI, air temperature observations are used, which are either mobile observations recorded with a moving vehicle mounted with data logger (dos Santos et al., 2017) or the meteorological station observations (Arnds et al., 2017). UHI varies both in space and time, as a function of various factors including canyon radiative geometry, thermal properties of materials, anthropogenic heat, urban greenhouse, reduction of evaporating surfaces, reduced turbulent transfer, climate, topography, physical layout of the built environment as well as short-term weather conditions (Golden and Kaloush, 2006; Shahmohamadi et al., 2011; Santamouris et al., 2019). Understanding of these factors is crucial for designing and implementing UHI mitigation solutions.

Understanding the UHI phenomenon for a city becomes crucial as it both directly and indirectly impacts human health (Vargo et al., 2016; Heaviside et al., 2017) through increased heat stress, and inflates the city's energy demands for cooling (Lowe, 2016; Liao et al., 2017). UHI and heat stress increase the building energy consumption by increasing the cooling demand in urban spaces. Literature shows that UHI causes median increase of $19 \%$ in cooling energy consumption (Li et al., 2019). However, there are huge inter-city variations ranging from $10-120 \%$ increases. Estimating this increase becomes essential given that India is a tropical country. Kumari et al. (2021) observed that UHI formation resulted in an increase of 2,600 GWh (i.e., 11.4\%) in
TABLE 1 | Search results on the keywords from various databases.

\begin{tabular}{|c|c|c|c|}
\hline Keywords & Google scholar & Sciencedirect & PubMed \\
\hline $\begin{array}{l}\text { "nature based } \\
\text { solutions" }\end{array}$ & 11,100 & 960 & 41 \\
\hline $\begin{array}{l}\text { "nature based } \\
\text { solutions" + "urban" }\end{array}$ & 7,830 & 727 & 16 \\
\hline $\begin{array}{l}\text { "nature based } \\
\text { solutions" + "urban } \\
\text { heat island" }\end{array}$ & 1,270 & 159 & 3 \\
\hline $\begin{array}{l}\text { "nature based solution" } \\
\text { + "air pollution" }\end{array}$ & 408 & 161 & 0 \\
\hline $\begin{array}{l}\text { "nature based solution" } \\
\text { + "urban heat island" } \\
\text { + "air pollution" }\end{array}$ & 190 & 76 & 0 \\
\hline
\end{tabular}

annual average electricity consumption in eight districts of Delhi between April 2012 to March 2017.

UHI has also been documented to increase the city's exposure to heatwaves under the global climate change scenario (Founda and Santamouris, 2017).With the changing climate scenario, many countries including India are becoming prone to more intense and frequent heat waves. Cities in particular due to the phenomenon of UHI, exhibit the synergies between urban heat and heatwave, making the urban areas more vulnerable to extreme heat. According to Sharma et al. (2019), frequency of heat waves for urban areas in Delhi is expected to increase from 0.8 times each summer season in current time frame to 2.1 and 5.1 times in short- and long-term projections. In the past few years researchers have focused on understanding the change in land surface temperature (LST) and factors influencing urban areas such as in Delhi (Mohan et al., 2012; Yadav and Sharma, 2018), Ahmedabad (Mathew et al., 2018), Bengaluru (Sussman et al., 2019), Jaipur (Mathew et al., 2018), Chennai (Swamy et al., 2017), Kochi (Thomas et al., 2014), Lucknow (Singh et al., 2017) and Mumbai (Dwivedi and Khire, 2018; Dwivedi et al., 2019).

Various measures for UHI have been explored particularly with contribution from studies by Mat Santamouris (Yang and Santamouris, 2018). These include, balancing the Albedo Effect in urban area and reduction of concrete urban surface (Icaza et al., 2017), planning and development of green belt and increasing of green cover in urban area (Huang et al., 2008), and installing green and white roofs (Detommaso et al., 2020).

\section{AIR POLLUTION EXPOSURE IN URBAN AREAS}

The megacities have emerged as engines of economic growth over the years but also as highly polluted urban sheds. The global urban population is expected to grow by $1.5 \%$ per year between 2025 and 2030. Some of the highest levels of outdoor air pollution in the world are recorded in Asian cities belonging to China and India (World Health Organization (WHO), 2016). Globally air pollution is a leading environmental risk factor resulting in an estimated 5 million deaths per year (Balakrishnan et al., 2019). According to WHO, about $80 \%$ of 
the urban population worldwide is exposed to air pollutant concentrations above the prescribed limits. Air pollution and related health impacts are critical in the urban environment due to its high population density and heterogeneity in emission sources resulting in pockets of very high pollutant concentration called as hotspots. The unplanned development in cities has led to the spatial variation in emission intensity which creates these local air quality control regions or hotspots. Globally, it is estimated that around $10 \%$ of the urban population lives in such hotspots (Akhtar and Palagiano, 2017). Urban air quality is largely affected by the micro-meteorology that governs the pollutant transport and resulting in hotspots. Due to the high spatial and temporal variability, the determination of air pollution hotspots is always a challenge in urban areas. Researchers have employed monitored data (fixed monitors, mobile monitors and sensors) (Kumar et al., 2015; Menon and Nagendra, 2018), satellite data (Chitranshi et al., 2015; Mahapatra et al., 2019), modeling and combined approaches (Xie et al., 2017; Mandal et al., 2020) to identify air pollution hotpots within the cities.

Other than the air pollutant emission sources, factors like UHI and climate change also affect urban air quality. Since climate change can affect the factors that govern pollutant transport like changes in chemical reaction rates and boundary layer mixing, it can have a significant effect on the regional air quality (Ebi and McGregor, 2008). According to Intergovernmental Panel on Climate Change (IPCC), elevated temperatures can have various other effects and can contribute to air pollution and related health effects (IPCC, 2013). An increase in air pollution exposure has been linked with a reduction in neighborhood greenery in the urban areas and its association with various health impacts such as cardiovascular diseases, premature mortality and children's health has been widely reported recently (Dadvand et al., 2015; Yitshak-Sade et al., 2017; Crouse et al., 2019).

\section{NATURE-BASED SOLUTIONS (NbS)}

$\mathrm{NbS}$ are gaining popularity in recent years in tackling environmental issues especially climate change and air pollution due to its potential co-benefits. The European Commission has defined NbS as "Solutions that are inspired and supported by nature, which are cost-effective, simultaneously provide environmental, social and economic benefits and help build resilience" (European Commission, n.d.). NbS are sustainable options to mitigate the harmful effects of climate change and pollution, improving the health and well-being of city residents at the same time benefiting biodiversity in the most resourceefficient way. Raymond et al. (2017) has developed a framework to assess the co-benefits of $\mathrm{NbS}$ emphasizing the need for a cross-sectoral approach to environmental policy and planning.

\section{NbS for Urban Heat Mitigation and Adaptation}

Vegetation cover has a larger effect in controlling temperature especially in urban areas as reported in various studies (Chen et al., 2020). Improving the vegetation cover/greenery is suggested as a way to mitigate UHI and air pollution as well as improving thermal comfort in urban areas. Native plant species tolerant to pollution with higher cooling potential are ideal choices as a common solution for the problem of air pollution and UHI. Thus, planners not only need to focus on the area under green cover, the spatial distribution of green cover but also the plant species that need to be planted when working on the mitigative solutions for air pollution and urban heat.

Green spaces have both local and global adaptation as well as mitigation impacts for climate change. They help in reducing the UHI effect at the city scale as well as reinforce carbon sequestration contributing to the mitigation of global climate change. These are often projected as a "soft engineering" strategy for climate adaptation (Kitha and Lyth, 2011) and also help in climate change adaptation and disaster risk reduction by providing ecosystem services (Munang et al., 2013). Such ecosystem-based approach is often widely reported as a costeffective tool in climate adaptation.

In addition, green cover and spaces offer numerous environmental advantages. They help improve the hydrology by preventing surface runoff (Zhang et al., 2015), as well as providing ground water recharge (Ramaiah and Avtar, 2019). These could also act as buffer to extreme events such as floods and help in providing climate adaptation by acting as natural storm water drains, thus reducing climate related disaster risks for cities (Bai et al., 2018). In terms of morphology, large green spaces areas with single composition have greater cooling effects (Kong et al., 2014). Various landscape matrices have been explored to understand the significance of morphology of the urban greens. LSI or the Landscape Shape Index is an important defining factor of the morphology of a green area in the city. For small sized green spaces with complex shapes, cooling intensity is usually limited or even negative in some instances (Jaganmohan et al., 2016). Apart from size, the shape of the green areas also influences their capacity to cool. For instance, circular green space has been observed to dissipate more heat than the square one (Yu et al., 2018). In addition, the vegetation configuration is also observed to influence the cooling capacity of the green spaces. Green spaces with trees have stronger cooling effect than grass. Moreover, in London, cooling distance has been found to positively influenced by the canopy height (Monteiro et al., 2016).

\section{NbS for Improving Air Quality}

Nature-based approaches could be effectively adopted as a cheaper and sustainable option in reducing exposure to particle and gaseous pollution in urban areas. can be used for monitoring air quality as well as mitigating air pollution. Some of the sensitive species such as lichens, algae, and trees have been used as bio-indicators of air quality. At the same time, some of the plant species have the potential to reduce air pollution through mechanisms such as bioaccumulation and deposition. The tolerance and sensitivity of the plant species vary depending on the type of stress (pollutant) and plant physiology. Air pollution Tolerance Index (APTI) is a measure developed by Singh and Rao to access the plant's tolerance to air pollutants (Singh and Rao, 1983). The plant species with high APTI 
value can be used to mitigate air pollution and the species with low APTI value can be used as bio-monitors due to their high sensitivity. Other than APTI, several other factors need to be considered depending on the requirement such as canopy structure, type of habitat, economic value etc. The trees with a good canopy and laminar structure can capture more dust and would be useful in removing dust. This is especially important in dusty environments such as roadsides. Tree species such as Dalbergia Sissoo and Polyalthia longifolia have good canopy structure as well as moderate to high APTI value. Meanwhile, tree species such as Mangifera indica and Azadirachta indica have economic value as well. Some of the studies have explored the possibility of estimating a new index taking into account all these factors which would help in identifying the ideal species (Pathak et al., 2011; Pandey et al., 2015a). The potential of some of the plant species in accumulating pollutants such as heavy metals has also been studied (Kumar et al., 2021). The metal accumulation species can be used in the green belt development in highly polluted areas such as industrial areas. Hence the careful selection of plant species based on their tolerance, physiological characteristics, and habitat will help in the mitigation of air pollution to a greater extent (Barwise and Kumar, 2020). Some of the commonly studied tree species for their air pollution tolerance and sensitivity in urban and industrial areas are given in Table 2.

In recent years, the term Green Infrastructure (GI) has been largely used by researchers referring to the introduction of vegetation into the urban landscape in the form of parks, green roofs, and walls and its effectiveness in reducing air pollution through various processes such as dispersion and deposition and climate change mitigation and adaptation. The World Health Organization(WHO) has recommended a green space per capita of 9 sq.m per person to improve the citizens' quality of life. Several countries such as UK and Malyasia have adopted standard-based approaches in ensuring green space availability. However, India lacks any stringent norms or standard-setting the minimum required green space per capita in urban areas. The urban Greening Guidelines 2014 by the Ministry of Urban Development suggested steps for the protection of trees and integrating green spaces in urban planning and development phases. Rapid urbanization has resulted in a considerable reduction of green cover in major Indian cities over the years. While some of the cities like Delhi have taken significant measures in restoring green spaces, most of the other cities still show a decreasing trend in their green cover. The green spaces in urban areas can be planned either by (a) using/restoring existing green areas or (b) designing new areas to meet the specific purpose in the form of parks, gardens, urban forests, roadside avenues, or vertical greening systems and green roofs.

\section{Vertical Greening Systems (VGS)}

VGS are structures where the vegetation is allowed to grow and spread over a wall or building. The potential of VGS in reducing the temperature, improving thermal comfort, energy savings and air pollution mitigation has been studied widely in the recent past (Pérez et al., 2014; Pandey et al., 2015b;
Bustami et al., 2018). VGS such as green facades and green walls can reduce the temperature by passive cooling and has been identified as a solution for urban heat islands. VGS will further help in energy savings by providing thermal insulation through its shade effect (reducing solar radiation), cooling effect (evapotranspiration of plants) and insulation effect (due to insulation of different layers) (Price et al., 2015). Based on the type of plants selected, these systems can mitigate air pollution as well. Some of the climber species with high APTI have been identified as ideal plant species for the development of VGS for air pollution mitigation (Pandey et al., 2015b). Thus, if carefully selected and designed, VGS can provide solutions to both climate change and air pollution in urban areas. Vertical gardens or VGS have recently gained much attention with most of the Indian cities installing them in highly polluted areas such as roadsides.

\section{Green Roofing}

Green roofing refers to the vegetation grown over the roof of a building. Green roofs can mitigate air pollution, UHI and noise, reduce energy consumption and, manage runoff water (Vijayaraghavan, 2016; Abhijith et al., 2017). Studies have shown that green roofs can substantially sequester carbon in plants through photosynthesis reducing ambient $\mathrm{CO}_{2}$ concentrations (Rowe, 2011).

\section{Need for an Integrated Approach}

Cities have a key role in resolving the sustainability challenges which have to be addressed through all the three pillars of sustainability-(Social) people, planet (Environmental) and profit (Economic). An integrated framework should be in place for assessing exposure, based on the atmospheric environmental quality of the cities and to identify vulnerable areas. This would require an understanding of the spatial and temporal distribution of thermal stress and air pollution in the city. It has been reported that India a has high potential for co-benefits of mitigation of air pollution and climate change. However, the knowledge on the interplay between these variables is still unclear. With intricate linkages between urban climate and air quality, it becomes important to understand their integrated exposure which could be of great interest for researchers in both health and climate studies. From practitioners' perspectives, such data could be of great help for urban planners in planning and designing sustainable cities.

\section{Proposed Framework for Implementing $\mathrm{NbS}$ in Urban Areas}

Identifying priority areas that require immediate attention is the major and foremost step. Both UHI and air pollution are reported to exhibit spatial as well as temporal (diurnal and seasonal) variations in urban areas. The large temperature variations in urban areas were attributed to various anthropogenic activities such as industries, transportation, air-conditioning and the urban design/geometry leading to changes in land use land cover (Gogoi et al., 2019). Air pollutants show large spatial and temporal variability depending on pollution sources, meteorology, microclimate and other factors. Hence hotspot mapping of air 
TABLE 2 | Air pollution tolerance and sensitivity of commonly studied plant species in Indian cities.

\begin{tabular}{|c|c|c|c|c|}
\hline Plant species & APTI value & Use & Location & Reference \\
\hline \multicolumn{5}{|c|}{ Urban areas } \\
\hline \multirow[t]{3}{*}{ Mangifera indica } & High & AP mitigation, Green belt development & Allahabad, UP & Kuddus et al. (2011) \\
\hline & & & Nanded, Maharashtra & Yannawar (2014) \\
\hline & & & Varanasi, UP & Pandey et al. (2016) \\
\hline \multirow[t]{3}{*}{ Azadirachta indica } & High to moderate & AP mitigation, & Allahabad, Gujarat & Kuddus et al. (2011) \\
\hline & & High dust deposition due to good & Nanded, Maharashtra & Yannawar (2014) \\
\hline & & foliage & Ahmedabad, Gujarat & Chaudhary and Rathore (2019) \\
\hline \multirow[t]{2}{*}{ Eucalyptus } & Moderate to sensitive & Can be used as bioindicator & Nanded, Maharashtra & Yannawar (2014) \\
\hline & & & Haridwar, Uttarakhand & Swami and Chauhan (2015) \\
\hline \multirow[t]{6}{*}{ Ficus religiosa } & High & Moderate dust removal capacity, & Allahabad, UP & Kuddus et al. (2011) \\
\hline & & Green belt development & Nanded, Maharashtra & Yannawar (2014) \\
\hline & & Excellent performer based on API & Gandhinagar, Gujarat & Chaudhary and Rathore (2018) \\
\hline & & (anticipated pollution index) & Varanasi, UP & Pathak et al. (2011) \\
\hline & & & & Pandey et al. (2015a) \\
\hline & & & Ahmedabad, Gujarat & Chaudhary and Rathore (2019) \\
\hline Dalbergia sissoo & Moderate & High dust removal capacity & Gandhinagar, Gujarat & Chaudhary and Rathore (2018) \\
\hline \multicolumn{5}{|c|}{ Industrial areas } \\
\hline Mangifera indica & Moderate & $\begin{array}{l}\text { Good dust capturing capacity, } \\
\text { Phytoextractor of copper }\end{array}$ & Jamshedpur, Jharkhand & Roy et al. (2020) \\
\hline Azadirachta indica & Moderate & Tolerant to AP & Jamshedpur, Jharkhand & Roy et al. (2020) \\
\hline \multirow[t]{2}{*}{ Ficus religiosa } & High & Tolerant to AP, Good dust capturing & Talkatora Industrial Area, UP & Bharti et al. (2018) \\
\hline & & capacity, Phytoextractor of copper & Jamshedpur, Jharkhand & Roy et al. (2020) \\
\hline Eucalyptus globus & High & Tolerant to AP & Talkatora Industrial Area, UP & Bharti et al. (2018) \\
\hline Bougainvillea sp & High & Tolerant to AP & Manali, Chennai & Ranjan et al. (2015) \\
\hline Shorea robusta & High & $\begin{array}{l}\text { Tolerant to AP and good metal } \\
\text { accumulation capacity }\end{array}$ & Bankura, West Bengal & Karmakar and Padhy (2019) \\
\hline
\end{tabular}

pollution also becomes imperative for understanding its spatial and temporal patterns and to identify Poor Air Quality (PAQ) pockets within the urban area. Spatio-temporal UHI maps (urban and non-urban pockets delineated using Local Climate Zones [LCZ]) and air quality maps (spatial distribution of air pollution) will help in identifying city hotspots for combined exposure to thermal stress and air pollution. In order to design appropriate adaptation strategies, it is essential to further the understanding of the city's vulnerabilities to the risks under consideration. Physiological heat stress affects productivity which could further decrease the adaptive capacity of vulnerable population. Hence, the vulnerable areas also need to be identified based on the socio-economic characteristics of the population. The selection of potential implementation areas and $\mathrm{NbS}$ in the identified priority location should go hand in hand and requires detailed planning (Albert et al., 2020). Various stakeholders including researchers, urban planners, ecologists and social scientists should be actively involved in the planning stage as the successful implementation depends on the landscape and land use characteristics, cost-effectiveness, funding, other societal and practical challenges as depicted in Figure 2.
The selection of NbS strategy mainly depends on the location characteristics such as major air pollution sources, urban/street morphology, aesthetic use and other benefits such as erosion prevention, noise mitigation, economic value etc. To start with, a database of trees for a particular city has to be developed which could be further classified based on tree physiological characteristics, APTI value and thermal performance. This will help in identifying and designing tree forms to achieve the required reduction in pollution and urban heat.

\section{Air Pollution Characteristics}

The plant species for green space development can be selected from the database based on the air pollution characteristics at the location. For example, if industrial pollution is prominent in the location, then pollutant-specific tolerant species can be selected for the development of the green belt. To curb vehicular pollution along the roads, the plants with good dust capturing potential and canopy could be selected along with high pollution tolerance. Vegetation can also be designed as a barrier to protect and separate people from pollution (Abhijith 


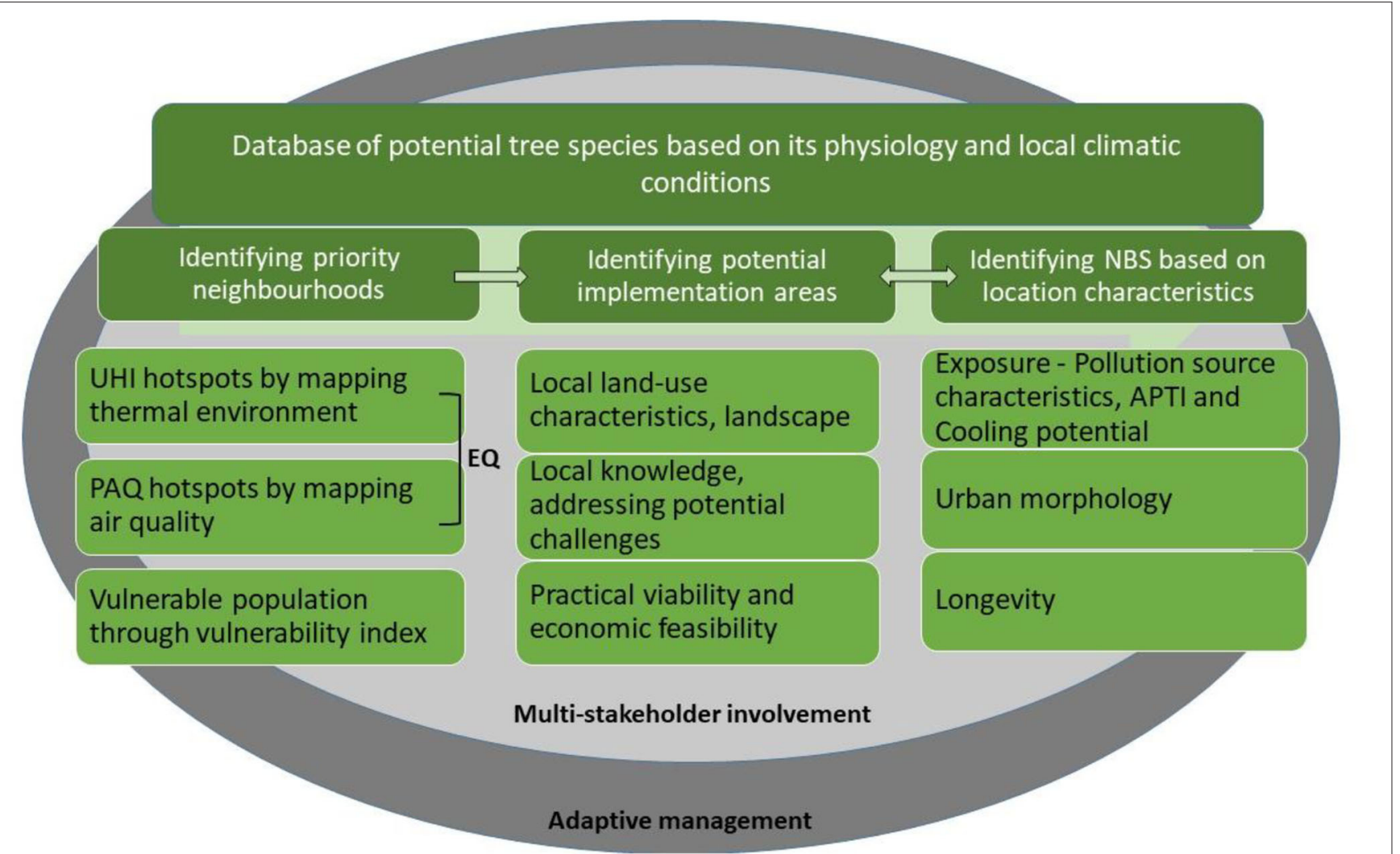

FIGURE 2 | Technical framework for NbS design in urban areas for co-mitigation of air pollution and urban heat (EQ- Environmental Quality).

et al., 2017; Barwise and Kumar, 2020). However, vegetation can sometimes hinder dispersion, thus building up pollutant concentration (Janhäll, 2015). A careful selection of plant species and design parameters as well as meteorological conditions play a major role in the successful mitigation of air pollution in urban areas (Leung et al., 2011).

\section{Thermal Reduction Potential}

The thermal performance of the selected plant species should be evaluated to determine the heat reduction potential (HRP) or cooling potential. This could be determined based on various indicators such as air temperature, thermal comfort or surface temperature. A recent study evaluated a methodological framework to select the trees for urban heat mitigation through parametric ENVI-met simulations using thermal comfort as an indicator for assessing the cooling potential of trees (Morakinyo et al., 2020). The study results indicated that a significant reduction in urban heat can be achieved by selecting right tree at the right place.

\section{Urban Morphology}

Urban morphology also has a greater role in the successful implementation of NbS strategies. The type of NbS strategy that could be adopted largely depends on the configuration of the urban area i.e., land use, available space, street configuration etc. As mentioned above, tall trees/vegetation is not recommended in street canyons as it can hinder free flow of air thus increasing air pollution and temperature (Janhäll, 2015). At the same time, properly designed green spaces could effectively mitigate UHI by improving natural cooling and, air pollution. In case of space constraints, other strategies such as VGS, green roofing, moss wall (a wall covered with moss) could be implemented. The reclamation of wastelands, landfills and dump yards in the form of parks/gardens are also commonly practiced widely in urban areas. Some of the examples from India include cities such as Delhi, Kolkata, and Bangalore.

\section{Longevity/Sustainability}

As vegetation is highly influenced by environmental stress, climate and various other factors such as soil type, water requirement etc, the suitability of plant species to each site determines its longevity (Barwise and Kumar, 2020). The native plant species exhibiting tolerance to environmental stresses experienced by the site as well as other factors as discussed above ensures sustainability and effectiveness of NbS strategies.

\section{Barriers in NbS Implementation}

Even though there has been an increased interest in NbS based approaches in recent years with a growing number of studies indicating its co-benefits, it is currently lacking actions at the implementation level. Governance plays a major role in the 
successful implementation of $\mathrm{NbS}$ (Li et al., 2021). Due to its multifunctionality, a participatory process is required with multi-stakeholder involvement and proper financial mechanisms to fund such approaches. In rapidly urbanizing nations like India, inadequate financial resources and space constraints are identified as major factors hindering its implementation (Singh et al., 2020a). The rapid developmental projects put immense pressure on cities in terms of space availability compromising the green spaces in urban areas. A recent report by UNEP estimated that globally, USD 133 billion/year is currently invested into NbS (using 2020 as the base year), which is considerably less than that flows to climate finance (United Nations Environment Programme, 2021). For countries like India, internationally comparable data on NbS financing is not available. The nationallevel policies in India on air pollution and climate change have individually allocated some funds for greening activities (under NCAP, INR 60.5 million is allocated for greening activities in 28 identified non-attainment cities), but lacks strategic planning. As NbS strategies are largely dependent on the local knowledge as well as socio-political conditions, adaptive governance is required based on the local knowledge and culture. This limits the decision-makers and funders from investing in this approach as they are not confident on its success and scalability. To address this challenge, recently the International Union for Conservation of Nature (IUCN) has established NbS global standard and self-assessment tool that will help to assess the effectiveness of NbS approaches (IUCN, 2020). IUCN has established a governance structure through an International Standard Committee and multistakeholder involvement. This will help in the effective mainstreaming and upscaling of $\mathrm{NbS}$ approaches into developmental planning and policies.

\section{REFERENCES}

Abhijith, K. V., Kumar, P., Gallagher, J., McNabola, A., Baldauf, R., Pilla, F., et al. (2017). Air pollution abatement performances of green infrastructure in open road and built-up street canyon environments - A review. Atmos. Environ. 162, 71-86. doi: 10.1016/j.atmosenv.2017.05.014

Akhtar, R., and Palagiano, C. (2017). Climate Change and Air Pollution: The Impact on Human Health in Developed and Developing Countries. New York, NY: Springer. doi: 10.1007/978-3-319-61346-8

Albert, C., Brillinger, M., Guerrero, P., Gottwald, S., Henze, J., Schmidt, S., et al. (2020). Planning nature-based solutions: principles, steps, and insights. Ambio 50, 1446-1461. doi: 10.1007/s13280-020-01365-1

Arnds, D., Böhner, J., and Bechtel, B. (2017). Spatio-temporal variance and meteorological drivers of the urban heat island in a European city. Theor. Appl. Climatol. 128, 43-61. doi: 10.1007/s00704-015-1687-4

Bai, T., Mayer, A. L., Shuster, W. D., and Tian, G. (2018). The hydrologic role of urban green space in mitigating flooding (Luohe, China). Sustainability 10:3584. doi: 10.3390/su10103584

Balakrishnan, K., Dey, S., Gupta, T., Dhaliwal, R. S., Brauer, M., Cohen, A. J., et al. (2019). The impact of air pollution on deaths, disease burden, and life expectancy across the states of India: the Global Burden of Disease Study 2017. Lancet Planet. Health 3, e26-e39. doi: 10.1016/S2542-5196(18)3 0261-4

Barwise, Y., and Kumar, P. (2020). Designing vegetation barriers for urban air pollution abatement: a practical review for appropriate plant species selection. Npj Climate Atmos. Sci. 3, 1-19. doi: 10.1038/s41612-020-0115-3

\section{CONCLUSION}

$\mathrm{NbS}$ have great potential in mitigating the harmful impacts of climate change and air pollution. However, to maximize the potential of $\mathrm{NbS}$ for combined mitigation of UHI and air pollution, proper planning in the implementation of these strategies is needed. NbS should be adapted to local conditions to be successful and effective. Recently greening strategies have been increasingly promoted through various schemes and programs on air pollution and climate change such as the National Mission for Green India as a part of the National Action Plan on Climate Change (NAPCC) and city clean air action plans and smart city plans, but lack a strategic approach to green space planning and management. Also, there is a need for developing strong evidence base on the effectiveness of $\mathrm{NbS}$, its co-benefits, and successful integration of green infrastructures into the city planning process, especially for a rapidly urbanizing country like India. Equitable access to green spaces has to be ensured for the sustainable and inclusive growth of cities. For example, socially disadvantaged groups are more prone to the negative impacts of air pollution and urban heat and likely to live in less green neighborhoods. Hence, NbS has to be integrated into the urban planning agenda providing a systematic approach including all the relevant stakeholders especially the citizens.

\section{AUTHOR CONTRIBUTIONS}

All authors listed have made a substantial, direct and intellectual contribution to the work, and approved it for publication.

Bharti, S. K., Trivedi, A., and Kumar, N. (2018). Air pollution tolerance index of plants growing near an industrial site. Urban Climate 24, 820-829. doi: 10.1016/j.uclim.2017.10.007

Bush, J., and Doyon, A. (2019). Building urban resilience with naturebased solutions: how can urban planning contribute? Cities 95:102483. doi: 10.1016/j.cities.2019.102483

Bustami, R. A., Belusko, M., Ward, J., and Beecham, S. (2018). Vertical greenery systems: a systematic review of research trends. Build. Environ. 146, 226-237. doi: 10.1016/j.buildenv.2018.09.045

Chaudhary, I. J., and Rathore, D. (2018). Suspended particulate matter deposition and its impact on urban trees. Atmos. Pollut. Res. 9, 1072-1082. doi: 10.1016/j.apr.2018.04.006

Chaudhary, I. J., and Rathore, D. (2019). Dust pollution: its removal and effect on foliage physiology of urban trees. Sustain. Cities Society 51:101696. doi: 10.1016/j.scs.2019.101696

Chen, M., Zhou, Y., Hu, M., and Zhou, Y. (2020). Influence of urban scale and urban expansion on the urban heat island effect in metropolitan areas: case study of Beijing-Tianjin-Hebei Urban agglomeration. Remote Sens. 12:3491. doi: 10.3390/rs12213491

Chitranshi, S., Sharma, S. P., and Dey, S. (2015). Satellite-based estimates of outdoor particulate pollution (PM10) for Agra City in northern India. Air Qual. Atmos. Health 8, 55-65. doi: 10.1007/s11869-014-0271-x

Crouse, D. L., Pinault, L., Balram, A., Brauer, M., Burnett, R. T., Martin, R. V., et al. (2019). Complex relationships between greenness, air pollution, and mortality in a population-based Canadian cohort. Environ. Int. 128, 292-300. doi: 10.1016/j.envint.2019.04.047 
Dadvand, P., Rivas, I., Basagaña, X., Alvarez-pedrerol, M., Su, J., Sunyer, J., et al. (2015). Science of the total environment the association between greenness and traf fi c-related air pollution at schools. Sci. Total Environ. 523, 59-63. doi: 10.1016/j.scitotenv.2015.03.103

De Ridder, K., Maiheu, B., Lauwaet, D., Daglis, I. A., Keramitsoglou, I., Kourtidis, K., et al. (2017). Urban heat island intensification during hot spells-The case of Paris during the summer of 2003. Urban Sci. 1:3. doi: 10.3390/urbansci10 10003

Detommaso, M., Cascone, S., Gagliano, A., Nocera, F., and Sciuto, G. (2020). "Cool roofs with variable thermal insulation: UHI mitigation and energy savings for several Italian cities," in Sustainability in Energy and Buildings, eds J. Littlewood, R. Howlett, A. Capozzoli, and L. Jain (Singapore: Springer), 481-492. doi: 10.1007/978-981-32-9868-2_41

Dihkan, M., Karsli, F., Guneroglu, N., and Guneroglu, A. (2018). Evaluation of urban heat island effect in Turkey. Arabian J. Geosci. 11:186. doi: $10.1007 / \mathrm{s} 12517-018-3972-\mathrm{x}$

Dirksen, M., Ronda, R., Theeuwes, N., and Pagani, G. (2019). Sky view factor calculations and its application in urban heat island studies. Urban Climate 30:100498. doi: 10.1016/j.uclim.2019.100498

dos Santos, R. S., Taylor, J., Davies, M., Mavrogianni, A., and Milner, J. (2017). "The variation of air and surface temperatures in London within a $1 \mathrm{~km}$ grid using vehicle-transect and ASTER data," in 2017 Joint Urban Remote Sensing Event (JURSE) (Dubai), 1-4. doi: 10.1109/JURSE.2017.7924613

Dwivedi, A., and Khire, M. (2018). Application of split-window algorithm to study Urban heat island effect in Mumbai through land surface temperature approach. Sustain. Cities Society 41, 865-877. doi: 10.1016/j.scs.2018.02.030

Dwivedi, A., Khire, M., Mohan, B., and Shah, S. (2019). The role of structure cooling to reduce the effect of urban heat island in Mumbai. Adv. Build. Energy Res. 13, 174-192. doi: 10.1080/17512549.2018.1488611

Ebi, K. L., and McGregor, G. (2008). Climate change, tropospheric ozone and particulate matter, and health impacts. Environ. Health Perspect. 116, 1449-1455. doi: 10.1289/ehp.11463

Estoque, R. C., and Murayama, Y. (2017). Monitoring surface urban heat island formation in a tropical mountain city using Landsat data (1987-2015). ISPRS J. Photogramm. Remote Sens. 133, 18-29. doi: 10.1016/j.isprsjprs.2017.09.008

European Commission (n.d.). Nature-Based Solutions. Available online at: https:// ec.europa.eu/info/researchand-innovation/researcharea/environment/naturebasedsolutions_en (accessed April 20, 2021).

Founda, D., and Santamouris, M. (2017). Synergies between urban heat island and heat waves in Athens (Greece), during an extremely hot summer (2012). Sci. Rep. 7, 1-11. doi: 10.1038/s41598-017-11407-6

Gaur, A., Eichenbaum, M. K., and Simonovic, S. P. (2018). Analysis and modelling of surface Urban Heat Island in 20 Canadian cities under climate and land-cover change. J. Environ. Manage. 206, 145-157. doi: 10.1016/j.jenvman.2017.10.002

Gogoi, P. P., Vinoj, V., Swain, D., Roberts, G., Dash, J., and Tripathy, S. (2019). Land use and land cover change effect on surface temperature over Eastern India. Sci. Rep. 9, 1-10. doi: 10.1038/s41598-019-45213-z

Golden, J. S., and Kaloush, K. E. (2006). Mesoscale and microscale evaluation of surface pavement impacts on the urban heat island effects. Int. J. Pavement Eng. 7, 37-52. doi: 10.1080/10298430500505325

Haashemi, S., Weng, Q., Darvishi, A., and Alavipanah, S. K. (2016). Seasonal variations of the surface urban heat island in a semi-arid city. Remote Sens.8:352. doi: $10.3390 / \mathrm{rs} 8040352$

Heaviside, C., Macintyre, H., and Vardoulakis, S. (2017). The urban heat island: implications for health in a changing environment. Curr; Environ. Health Rep. 4, 296-305. doi: 10.1007/s40572-017-0150-3

Huang, L., Li, J., Zhao, D., and Zhu, J. (2008). A fieldwork study on the diurnal changes of urban microclimate in four types of ground cover and urban heat island of Nanjing, China. Build. Environ. 43, 7-17. doi: 10.1016/j.buildenv.2006.11.025

Icaza, L. E., van der Hoeven, F., and van den Dobbelsteen, A. (2017). The urban heat island effect in Dutch city centres. Archit. Built Environ. 20, 161-202. doi: 10.7480/abe.2017.20.3472

IPCC (2013). AR5 - Summary for policymakers. Climate Change 2013 - The physical science basis, contribution of working group I to the fifth assessment report of the intergovernmental panel on climate change. 78-78.
IUCN (2020). Global Standard for Nature-based Solutions. A User-Friendly Framework for the Verification, Design and Scaling up of NbS. Gland, Switzerland: IUCN.

Jaganmohan, M., Knapp, S., Buchmann, C. M., and Schwarz, N. (2016). The bigger, the better? The influence of urban green space design on cooling effects for residential areas. J. Environ. Qual. 45, 134-145. doi: 10.2134/jeq2015.01.0062

Janhäll, S. (2015). Review on urban vegetation and particle air pollution - Deposition and dispersion. Atmos. Environ. 105, 130-137. doi: 10.1016/j.atmosenv.2015.01.052

Karmakar, D., and Padhy, P. K. (2019). Air pollution tolerance, anticipated performance, and metal accumulation indices of plant species for greenbelt development in urban industrial area. Chemosphere 237:124522. doi: 10.1016/j.chemosphere.2019.124522

Kitha, J., and Lyth, A. (2011). Urban wildscapes and green spaces in Mombasa and their potential contribution to climate change adaptation and mitigation. Environ. Urban. 23, 251-265. doi: 10.1177/0956247810396054

Kong, F., Yin, H., James, P., Hutyra, L. R., and He, H. S. (2014). Effects of spatial pattern of greenspace on urban cooling in a large metropolitan area of eastern China. Landsc. Urban Plan. 128, 35-47. doi: 10.1016/j.landurbplan.2014.04.018

Kuddus, M., Kumari, R., and Ramteke, P. W. (2011). Studies on air pollution tolerance of selected plants in Allahabad city, India. J. Environ. Res. Manage. 2, 42-46. Available online at: https://www.e3journals.org/cms/articles/ 1330779058_Mohammed\%20et\%20al.pdf

Kumar, A., Kumar, P., Singh, H., and Kumar, N. (2021). Adaptation and mitigation potential of roadside trees with bio-extraction of heavy metals under vehicular emissions and their impact on physiological traits during seasonal regimes. Urban For. Urban Green. 58:126900. doi: 10.1016/j.ufug.2020.126900

Kumar, P., Morawska, L., Martani, C., Biskos, G., Neophytou, M., Di Sabatino, S., et al. (2015). The rise of low-cost sensing for managing air pollution in cities. Environ. Int. 75, 199-205. doi: 10.1016/j.envint.2014.11.019

Kumari, P., Garg, V., Kumar, R., and Kumar, K. (2021). Impact of urban heat island formation on energy consumption in Delhi. Urban Climate 36, 100763. doi: $10.1016 /$ j.uclim.2020.100763

Leung, D. Y. C., Tsui, J. K. Y., Chen, F., Yip, W.-K., Vrijmoed, L. L. P., and Liu, C.-H. (2011). Effects of Urban Vegetation on Urban Air Quality. Landsc. Res. 36, 173-188. doi: 10.1080/01426397.2010.547570

Li, G., Zhang, X., Mirzaei, P. A., Zhang, J., and Zhao, Z. (2018). Urban heat island effect of a typical valley city in China: responds to the global warming and rapid urbanization. Sustain. Cities Society 38, 736-745. doi: 10.1016/j.scs.2018.01.033

Li, L., Cheshmehzangi, A., Ka, F., Chan, S., and Ives, C. D. (2021). Mapping the Research Landscape of Nature-Based Solutions in Urbanism. Sustainability 13:3876. doi: $10.3390 /$ su13073876

Li, X., Zhou, Y., Yu, S., Jia, G., Li, H., and Li, W. (2019). Urban heat island impacts on building energy consumption: a review of approaches and findings. Energy 174, 407-419. doi: 10.1016/j.energy.2019.02.183

Liao, W., Liu, X., Wang, D., and Sheng, Y. (2017). The impact of energy consumption on the surface urban heat island in China's 32 major cities. Remote Sens. 9:250. doi: 10.3390/rs9030250

Lowe, S. A. (2016). An energy and mortality impact assessment of the urban heat island in the US. Environ. Impact Assess. Rev. 56, 139-144. doi: 10.1016/j.eiar.2015.10.004

Mahapatra, P. S., Puppala, S. P., Adhikary, B., Shrestha, K. L., Dawadi, D. P., Paudel, S. P., et al. (2019). Air quality trends of the Kathmandu Valley: a satellite, observation and modeling perspective. Atmos. Environ. 201, 334-347. doi: 10.1016/j.atmosenv.2018.12.043

Mandal, S., Madhipatla, K. K., Guttikunda, S., Kloog, I., Prabhakaran, D., and Schwartz, J. D. (2020). Ensemble averaging based assessment of spatiotemporal variations in ambient PM2.5 concentrations over Delhi, India, during 2010-2016. Atmos. Environ. 224:117309. doi: 10.1016/j.atmosenv.2020.1 17309

Manisalidis, I., Stavropoulou, E., Stavropoulos, A., and Bezirtzoglou, E. (2020). Environmental and health impacts of air pollution: a review. Front. Public Health 8, 14-14. doi: 10.3389/fpubh.2020.00014

Mathew, A., Khandelwal, S., Kaul, N., and Chauhan, S. (2018). Analyzing the diurnal variations of land surface temperatures for surface urban heat island studies: Is time of observation of remote sensing data important? Sustain. Cities Society 40, 194-213. doi: 10.1016/j.scs.2018.03.032 
Menon, J. S., and Nagendra, S. M. S. (2018). Personal exposure to fine particulate matter concentrations in central business district of a tropical coastal city. J. Air Waste Manage. Assoc. 68, 415-429. doi: 10.1080/10962247.2017.14 07837

Mohajerani, A., Bakaric, J., and Jeffrey-Bailey, T. (2017). The urban heat island effect, its causes, and mitigation, with reference to the thermal properties of asphalt concrete. J. Environ. Manage. 197, 522-538. doi: 10.1016/j.jenvman.2017.03.095

Mohan, M., Kikegawa, Y., Gurjar, B., Bhati, S., Kandya, A., and Ogawa, K. (2012). Urban heat island assessment for a tropical urban airshed in India. Atmos. Clim. Sci. 2, 127-138. doi: 10.4236/acs.2012.22014

Monteiro, M. V., Doick, K. J., Handley, P., and Peace, A. (2016). The impact of greenspace size on the extent of local nocturnal air temperature cooling in London. Urban For. Urban Green. 16, 160-169. doi: 10.1016/j.ufug.2016. 02.008

Morakinyo, T. E., Ouyang, W., Lau, K. K.-L., Ren, C., and Ng, E. (2020). Right tree, right place (urban canyon): Tree species selection approach for optimum urban heat mitigation - development and evaluation. Sci. Total Environ. 719:137461. doi: 10.1016/j.scitotenv.2020.137461

Munang, R., Thiaw, I., Alverson, K., Liu, J., and Han, Z. (2013). The role of ecosystem services in climate change adaptation and disaster risk reduction. Curr. Opin. Environ. Sustain. 5, 47-52. doi: 10.1016/j.cosust.2013. 02.002

Oke, T. R. (1973). City size and the urban heat island. Atmos. Environ. (1967) 7, 769-779. doi: 10.1016/0004-6981(73)90140-6

Pandey, A. K., Pandey, M., Mishra, A., Tiwary, S. M., and Tripathi, B. D. (2015a). Air pollution tolerance index and anticipated performance index of some plant species for development of urban forest. Urban For. Urban Green. 14, 866-871. doi: 10.1016/j.ufug.2015.08.001

Pandey, A. K., Pandey, M., and Tripathi, B. D. (2015b). Air pollution tolerance index of climber plant species to develop vertical greenery systems in a polluted tropical city. Landsc. Urban Plan. 144, 119-127. doi: 10.1016/j.landurbplan.2015.08.014

Pandey, A. K., Pandey, M., and Tripathi, B. D. (2016). Assessment of air pollution tolerance index of some plants to develop vertical gardens near street canyons of a polluted tropical city. Ecotoxicol. Environ. Saf. 134, 358-364. doi: 10.1016/j.ecoenv.2015.08.028

Pathak, V., Tripathi, B. D., and Mishra, V. K. (2011). Evaluation of anticipated performance index of some tree species for green belt development to mitigate traffic generated noise. Urban For. Urban Green. 10, 61-66. doi: 10.1016/j.ufug.2010.06.008

Pérez, G., Coma, J., Martorell, I., and Cabeza, L. F. (2014). Vertical Greenery Systems (VGS) for energy saving in buildings: a review. Renew. Sustain. Energy Rev. 39, 139-165. doi: 10.1016/j.rser.2014.07.055

Price, A., Jones, E. C., and Jefferson, F. (2015). Vertical Greenery Systems as a strategy in urban heat island mitigation. Water Air Soil Pollut. 226:247. doi: 10.1007/s11270-015-2464-9

Qaid, A., Lamit, H. B., Ossen, D. R., and Shahminan, R. N. R. (2016). Urban heat island and thermal comfort conditions at micro-climate scale in a tropical planned city. Energy Build. 133, 577-595. doi: 10.1016/j.enbuild.2016.10.006

Ramaiah, M., and Avtar, R. (2019). Urban green spaces and their need in cities of rapidly urbanizing India: a review. Urban Sci. 3:94. doi: 10.3390/urbansci3030094

Ramamurthy, P., and Sangobanwo, M. (2016). Inter-annual variability in urban heat island intensity over 10 major cities in the United States. Sustain. Cities Society 26, 65-75. doi: 10.1016/j.scs.2016.05.012

Ranagalage, M., Dissanayake, D., Murayama, Y., Zhang, X., Estoque, R., Perera, E., et al. (2018). Quantifying surface urban heat island formation in the world heritage tropical mountain city of Sri Lanka. ISPRS Int. J. Geo-Inf. 7:341. doi: 10.3390/ijgi7090341

Ranjan, O., Menon, J. S., Nagendra, S. M. S., Ph, D., and Asce, M. (2015). Assessment of air quality impacts on human health and vegetation at an industrial area. J. Hazard. Toxic Radioact. Waste 20, 1-10. doi: 10.1061/(ASCE)HZ.2153-5515.0000316

Raymond, C. M., Frantzeskaki, N., Kabisch, N., Berry, P., Breil, M., Nita, M. R., et al. (2017). A framework for assessing and implementing the co-benefits of nature-based solutions in urban areas. Environ. Sci. Policy 77, 15-24. doi: 10.1016/j.envsci.2017.07.008
Rizvi, S. H., Alam, K., and Iqbal, M. J. (2019). Spatio-temporal variations in urban heat island and its interaction with heat wave. J. Atmos. Solar Terrestrial Physics 185, 50-57. doi: 10.1016/j.jastp.2019.02.001

Rowe, D. B. (2011). Green roofs as a means of pollution abatement. Environ. Pollut. 159, 2100-2110. doi: 10.1016/j.envpol.2010.10.029

Roy, A., Bhattacharya, T., and Kumari, M. (2020). Air pollution tolerance, metal accumulation and dust capturing capacity of common tropical trees in commercial and industrial sites. Sci. Total Environ. 722:137622. doi: 10.1016/j.scitotenv.2020.137622

Sagris, V., and Sepp, M. (2017). Landsat-8 TIRS data for assessing urban heat island effect and its impact on human health. IEEE Geosci. Remote Sens. Lett. 14, 2385-2389. doi: 10.1109/LGRS.2017.2765703

Santamouris, M., Ding, L., and Osmond, P. (2019). "Urban heat island mitigation," in Decarbonising the Built Environment (Singapore: Palgrave Macmillan), 337355. doi: 10.1007/978-981-13-7940-6_18

Santamouris, M., Haddad, S., Fiorito, F., Osmond, P., Ding, L., Prasad, D., et al. (2017). Urban heat island and overheating characteristics in Sydney, Australia. An analysis of multiyear measurements. Sustainability 9:712. doi: 10.3390/su9050712

Shahmohamadi, P., Che-Ani, A., Maulud, K., Tawil, N., and Abdullah, N. (2011). The impact of anthropogenic heat on formation of urban heat island and energy consumption balance. Urban Stud. Res. 2011:497524. doi: 10.1155/2011/497524

Sharma, R., Hooyberghs, H., Lauwaet, D., and De Ridder, K. (2019). Urban heat island and future climate change-Implications for Delhi's heat. J. Urban Health 96, 235-251. doi: 10.1007/s11524-018-0322-y

Sidiqui, P., Huete, A., and Devadas, R. (2016). "Spatio-temporal mapping and monitoring of Urban Heat Island patterns over Sydney, Australia using MODIS and Landsat-8," in 2016 4th International Workshop on Earth Observation and Remote Sensing Applications (EORSA) (Guangzhou), 217-221. doi: 10.1109/EORSA.2016.7552800

Singh, A., Sarma, A. K., and Hack, J. (2020a). Cost-Effective Optimization of Nature-Based Solutions for Reducing Urban Floods Considering Limited Space Availability. Environ. Process. 7, 297-319. doi: 10.1007/s40710-019-00420-8

Singh, P., Kikon, N., and Verma, P. (2017). Impact of land use change and urbanization on urban heat island in Lucknow city, Central India. A remote sensing based estimate. Sustain. Cities Soc. 32, 100-114. doi: 10.1016/j.scs.2017.02.018

Singh, S. K., and Rao, D. N. (1983). "Evaluation of plants for their tolerance to air pollution," in Proceedings of Symposium on Air Pollution Control, Vol. 1, $218-224$.

Singh, V. K., Acero, J. A., and Martilli, A. (2020b). Evaluation of the impact of anthropogenic heat emissions generated from road transportation and power plants on the UHI intensity of Singapore. Technical Report Cooling Singapore. Singapore-ETH Centre (SEC).

Sussman, H. S., Raghavendra, A., and Zhou, L. (2019). Impacts of increased urbanization on surface temperature, vegetation, and aerosols over Bengaluru, India. Remote Sens. Appl. Society Environ. 16:100261. doi: 10.1016/j.rsase.2019.100261

Swami, A., and Chauhan, D. (2015). Impact of air pollution induced by automobile exhaust pollution on air pollution tolerance index (APTI) on few species of plants. Int. J. Sci. Res. 4, 342-343. doi: 10.15373/22778179\#sthash.vF0KMdSC.dpuf

Swamy, G., Nagendra, S. S., and Schlink, U. (2017). Urban heat island (UHI) influence on secondary pollutant formation in a tropical humid environment. J. Air Waste Manage. Assoc. 67, 1080-1091. doi: 10.1080/10962247.2017.13 25417

Thomas, G., Sherin, A., Ansar, S., and Zachariah, E. (2014). Analysis of urban heat island in Kochi, India, using a modified local climate zone classification. Proc. Environ. Sci. 21, 3-13. doi: 10.1016/j.proenv.2014. 09.002

Ulpiani, G. (2021). On the linkage between urban heat island and urban pollution island: three-decade literature review towards a conceptual framework. Sci. Total Environ. 751:141727. doi: 10.1016/j.scitotenv.2020.1 41727

United Nations Environment Programme (2021). State of Finance for Nature 2021 Nairobi: United Nations Environment Programme (UNEP).

Vargo, J., Stone, B., Habeeb, D., Liu, P., and Russell, A. (2016). The social and spatial distribution of temperature-related health impacts from 
urban heat island reduction policies. Environ. Sci. Policy 66, 366-374. doi: 10.1016/j.envsci.2016.08.012

Vijayaraghavan, K. (2016). Green roofs: a critical review on the role of components, benefits, limitations and trends. Renew. Sustain. Energy Rev. 57, 740-752. doi: 10.1016/j.rser.2015.12.119

Weng, Q., Firozjaei, M. K., Sedighi, A., Kiavarz, M., and Alavipanah, S. K. (2019). Statistical analysis of surface urban heat island intensity variations: a case study of Babol city, Iran. GISci. Remote Sens. 56, 576-604. doi: 10.1080/15481603.2018.1548080

World Health Organization (WHO) (2016). WHO Global Urban Ambient Air Pollution Database. Geneva: World Health Organization.

Xie, X., Semanjski, I., Gautama, S., Tsiligianni, E., Deligiannis, N., Rajan, R. T., et al. (2017). A review of urban air pollution monitoring and exposure assessment methods. ISPRS Int. J. Geo-Inf. 6, 1-21. doi: 10.3390/ijgi6120389

Yadav, N., and Sharma, C. (2018). Spatial variations of intra-city urban heat island in megacity Delhi. Sustain. Cities Society 37, 298-306. doi: $10.1016 /$ j.scs.2017.11.026

Yang, J., and Santamouris, M. (2018). Urban heat island and mitigation technologies in Asian and Australian cities-impact and mitigation. Urban Sci. 2:74. doi: 10.3390/urbansci2030074

Yannawar, V. (2014). Air pollution tolerance index of various plant species around Nanded City of Maharashtra, India. J. Appl. Phytotechnol. Environ. Sanit. 3, 23-28.

Yitshak-Sade, M., Kloog, I., and Novack, V. (2017). Do air pollution and neighborhood greenness exposures improve the predicted cardiovascular risk? Environ. Int. 107, 147-153. doi: 10.1016/j.envint.2017.07.011
Yu, Z., Guo, X., Zeng, Y., Koga, M., and Vejre, H. (2018). Variations in land surface temperature and cooling efficiency of green space in rapid urbanization: the case of Fuzhou city, China. Urban For. Urban Green. 29, 113-121. doi: 10.1016/j.ufug.2017.11.008

Zhang, B., Li, N., and Wang, S. (2015). Effect of urban green space changes on the role of rainwater runoff reduction in Beijing, China. Landsc. Urban Plan. 140, 8-16. doi: 10.1016/j.landurbplan.2015. 03.014

Conflict of Interest: The authors declare that the research was conducted in the absence of any commercial or financial relationships that could be construed as a potential conflict of interest.

Publisher's Note: All claims expressed in this article are solely those of the authors and do not necessarily represent those of their affiliated organizations, or those of the publisher, the editors and the reviewers. Any product that may be evaluated in this article, or claim that may be made by its manufacturer, is not guaranteed or endorsed by the publisher.

Copyright (c) 2021 Menon and Sharma. This is an open-access article distributed under the terms of the Creative Commons Attribution License (CC BY). The use, distribution or reproduction in other forums is permitted, provided the original author(s) and the copyright owner(s) are credited and that the original publication in this journal is cited, in accordance with accepted academic practice. No use, distribution or reproduction is permitted which does not comply with these terms. 